\title{
High HIV incidence among male injection drug users in Delhi,
} India

Waimar Tun

Population Council

Lopamudra Saraswati

Mary Philip Sebastian

Population Council

Vartika Sharma

Population Council

Amita Yadav

See next page for additional authors

Follow this and additional works at: https://knowledgecommons.popcouncil.org/departments_sbsr-hiv

Part of the Demography, Population, and Ecology Commons, Family, Life Course, and Society Commons, International Public Health Commons, Medicine and Health Commons, and the Substance Abuse and Addiction Commons

How does access to this work benefit you? Let us know!

\section{Recommended Citation}

Tun, Waimar, Lopamudra Saraswati, Mary Philip Sebastian, Vartika Sharma, Amita Yadav, Ira Madan, Ibou Thior, and Avina Sarna. 2013. "High HIV incidence among male injection drug users in Delhi, India," Research update. New Delhi: Population Council. 


\section{Authors}

Waimar Tun, Lopamudra Saraswati, Mary Philip Sebastian, Vartika Sharma, Amita Yadav, Ira Madan, Ibou Thior, and Avina Sarna 
India has a large injection drug user (IDU) population estimated at 177,000 . The overall national HIV prevalence is around 7.2 percent in this group, which is the highest among all key populations in the country including antenatal care attendees, female sex workers, men who have sex with men and patients at sexually transmitted infection (STI) clinics. ${ }^{1,2}$ While there is information available on HIV prevalence from different regions of the country, there is limited HIV incidence data among IDUs in India.

In collaboration with Arise-Enhancing HIV Prevention Programs for At-Risk Populations, the Population Council initiated a prospective cohort study at five centers operated by Sahara Centre for Rehabilitation and Residential Care (SAHARA) in Delhi to examine HIV incidence and behavior change pre-introduction (control phase) and post-introduction (intervention phase) of HIV prevention services among IDUs. The study entails three rounds of data collection: baseline, follow-up visit 1 (FV1) and follow-up visit 2 (FV2) at the end of the study. Here we report the HIV incidence and correlates of incident HIV infections in the HIV-negative male IDUs cohort during the control phase.

\section{Study Methodology}

The baseline assessment was undertaken from May to October 2011 at five sites operated by SAHARA within Delhi. Participants were recruited through peer-referral (26.3 percent), targeted outreach by outreach workers (53.6 percent), and walk-ins (20.1 percent). Eligibility criteria included being at least 18 years of age, residing in and around Delhi, and having injected drugs at least once in the last three months. A total of 3,792 males, including 10 transgender, were recruited into the study. As very few female IDUs $(n=26)$ were recruited in the study at base- line, they have been excluded from the analysis. Only HIV negative male IDUs have been included in the incidence analysis. Trained research interviewers administered a close-ended questionnaire in Hindi to collect data on socio demographic characteristics, injecting practices, sexual behaviours, knowledge of HIV and utilization of harm reduction services.

HIV serostatus at baseline was determined using NACO guidelines using rapid tests: HIV-negative status was based on a single highly sensitive rapid test and a positive result on two additional confirmatory rapid tests. At FV1, all HIV-negative male IDUs were tested using a fourth generation Antigen-Antibody test followed by a confirmatory Western Blot Assay. For participants who tested positive on Western Blot at FV1, their HIV-negative status at baseline was confirmed to rule out any window period HIV infection at baseline using a fourth generation Antigen-Antibody test on a stored serum sample. For participants with a negative or indeterminate result on the Western blot test at FV1, a plasma HIV PCR RNA test was conducted on the FV1 plasma sample to identify any window period infection at FV1.

\section{Analysis}

HIV incidence rate was calculated over the control phase (date of FV1-date of baseline) by dividing the number of new infections by the total person-years of follow-up. Sero-conversion date was taken to be the date of HIV test at FV1 visit. Bivariate and multivariate analyses using Cox proportional hazard ratios were conducted to determine behavioral factors associated with incident HIV infections after controlling for age, education, marital status and accommodation.

\section{\%: PATH




\section{Study Population}

Of the 2,790 eligible male HIV-negative IDUs recruited at baseline, 1,880 (67.4 percent) HIV-negative male IDUs returned for their FV1 visit. Among those, HIV testing was conducted for 1,806 (96 percent) and behavioral survey completed. The median follow-up time among participants was 9.7 months (IQR: 8.1, 11.1). The median age was 28 years [IQR: 23,38 ]. About one-half (47.7 percent) were illiterate, and 53.5 percent were never married.

IDUs were living with family or relatives (43.9 percent), living on the street or slum (39.5 percent) or living in rented home or were a paying guest (16.6 percent).

\section{Key Findings}

\section{High HIV incidence among male IDUs in Delhi}

A total of 112 new HIV infections occurred over a cumulative 1,443.76 person-years of follow-up resulting in an incidence rate of 7.76 new infections per 100 person-years (95 percent $\mathrm{Cl}: 6.45-9.34)$.

\section{Risky injection practices were common among newly HIV-infected IDUs}

Among the 112 newly HIV-infected participants, 74 percent $(n=83)$ reported risky injection behaviors' in the last month preceding FV1. These high-risk practices in conjunction with the high HIV prevalence are fueling the HIV incidence.

\section{Risky injection practices associated with higher risk of HIV}

On multivariate analysis, after controlling for age, education, marital status and accommodation, risky injection behaviors (Hazard risk ratio [HRR] 2.76; 95 percent $\mathrm{Cl}$ 1.54-4.93), injecting smack/brown sugar (HRR: 2.43; 95 percent $\mathrm{Cl}$ : 1.53-3.87) were significantly associated with a higher risk of new infections. Injection with tranquilizers were associated with a lower risk of new infections (HRR: 0.53; 95 percent $\mathrm{Cl}$ : 0.32-0.86; $\mathrm{p}=0.01$ ).

'A 5-item 'Risky Injection Behavior' index was derived from various injection practices in the last one month: (i) Using needles or syringes previously used by someone else; (ii) Back/ front loading/splitting drugs (iii) Shared vial, cooker, container, cotton, filter or water; (iv) Receiving an injection with syringe filled by someone else; and (v) Drawing up drugs from a common container.
Sex partners at high risk of HIV infection

Although sexual activity was not associated with risk of incident infections, of the 112 participants with new infections, 20.5 percent reported unsafe sex with a female partner in the three months preceding the survey.

\section{Conclusion and Program Implications} HIV transmission risk remains high among IDUs in Delhi despite targeted prevention interventions for this population. The incidence of 7.76 per 100 person-years among male IDUs in Delhi is higher than other cities with established HIV epidemic among IDUs such as St. Petersburg, Russia (4.5 per 100 person-years) and Bangkok, Thailand (5.8 per 100 person-years), but is comparable to the incidence among IDUs in Xinjiang, China (8.8 per 100 person-years). ${ }^{3-5}$

Despite the widespread availability of free sterile needles and syringes from needle exchange programs (NSEP) and targeted interventions with harm reduction messages, HIV risk is primarily associated with risky drug injection practices. Only a small proportion of our cohort reported accessing NSEP services and only 10 percent reported accessing opioid substitution therapy in the month preceding the survey. Therefore, targeted intervention programs must find ways to: i) increase regular access to harm reduction services; and ii) that use of services actually translates to changed behaviors.

This study also demonstrates that a large number of IDUs can be enrolled into a prevention study with reasonable rate of follow-up. Thus, this population should be considered for future HIV prevention trials.

\section{References}

${ }^{1}$ National AIDS Control Organization (NACO), Department of AIDS Control, Ministry of Health and Family Welfare. 2012. "Annual Report: 2011-2012." New Delhi: NACO.

${ }^{2}$ National AIDS Control Organization (NACO), Department of AIDS Control, Ministry of Health and Family Welfare, Government of India. 2012. "HIV sentinel surveillance 2010-11: A technical brief." New Delhi: NACO. ${ }^{3}$ Kozlov, A.P. et al. 2006. "HIV incidence and factors associated with HIV acquisition among injection drug users in St Petersburg, Russia," AIDS 20(6): 901-906.

${ }^{4}$ Zhang, Y. et al. 2007. "HIV incidence, retention rate, and baseline predictors of HIV incidence and retention in a prospective cohort study of injection drug users in Xinjiang, China," Int J Infect Dis 11(4): 318-323.

${ }^{5}$ Vanichseni, S. et al. 2001. "Continued high HIV-1 incidence in a vaccine trial preparatory cohort of injection drug users in Bangkok, Thailand," AIDS 15(3): $397-405$.

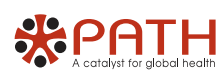

Canadà

Support for this project was provided by the Arise Program-Enhancing HIV Prevention Programs for At-Risk Populations, through financial support provided by the Canadian Government through the Canadian International Development Agency, and via financial and technical support provided by PATH. The views expressed by the authors do not necessarily reflect the views of PATH, the Canadian Government, or the Canadian International Development Agency.

\section{P Population Council}

The Population Council confronts critical health and development issues-from stopping the spread of HIV to improving reproductive health and ensuring that young people lead full and productive lives. Through biomedical, social science and public health research in about 50 countries, the Council works with our partners to deliver solutions that lead to more effective policies, programs, and technologies to improve lives worldwide. Established in 1952 and headquartered in New York, the Council is a nongovernmental, nonprofit organization with an international board of trustees.

Suggested citation: Tun, Waimar, Lopamudra Saraswati, Mary Sebastian, Vartika Sharma, Amita Yadav, Ira Madan, Ibou Thior, and Avina Sarna. 2013. "High HIV incidence among male injection drug users in Delhi, India," Research Update. Delhi: Population Council. 